\section{OPEN ACCESS}

Edited by:

Haldre S. Rogers,

lowa State University, United States

Reviewed by:

Evan Rehm,

Austin Peay State University,

United States

Kim McConkey,

National Institute of Advanced

Studies, India

*Correspondence:

Onja H. Razafindratsima

onja@berkeley.edu

Specialty section:

This article was submitted to

Population, Community,

and Ecosystem Dynamics,

a section of the journal

Frontiers in Ecology and Evolution

Received: 18 January 2021

Accepted: 26 August 2021

Published: 16 September 2021

Citation:

Razafindratsima $\mathrm{OH}$,

Raoelinjanakolona NN, Heriniaina RR, Nantenaina $\mathrm{RH}$, Ratolojanahary $\mathrm{TH}$ and Dunham AE (2021) Simplified Communities of Seed-Dispersers Limit the Composition and Flow

of Seeds in Edge Habitats.

Front. Ecol. Evol. 9:655441.

doi: 10.3389/fevo.2021.655441

\title{
Simplified Communities of Seed-Dispersers Limit the Composition and Flow of Seeds in Edge Habitats
}

\author{
Onja H. Razafindratsima ${ }^{1 *}$, Nasandratra Nancia Raoelinjanakolona², Rio R. Heriniaina ${ }^{3,4}$, \\ Rindra H. Nantenaina ${ }^{5}$, Tianasoa H. Ratolojanahary' ${ }^{6}$ and Amy E. Dunham ${ }^{7}$
}

${ }^{1}$ Department of Integrative Biology, University of California, Berkeley, Berkeley, CA, United States, ${ }^{2}$ Mention Zoologie et Biodiversité Animale, Université d'Antananarivo, Antananarivo, Madagascar, ${ }^{3}$ Mention Sciences Expérimentales et Valorisation des Ressources Naturelles, Ecole Normale Supérieure, Université d'Antananarivo, Antananarivo, Madagascar, ${ }^{4}$ Association Vinako for Madagascar, Antananarivo, Madagascar, ${ }^{5}$ Mention Biologie et Ecologie Végétale, Université d'Antananarivo, Antananarivo, Madagascar, ${ }^{6}$ Association Mitsinjo, Andasibe, Madagascar, ${ }^{7}$ Department of Biosciences, Rice University, Houston, TX, United States

Edge effects, driven by human modification of landscapes, can have critical impacts on ecological processes such as species interactions, with cascading impacts on biodiversity as a whole. Characterizing how edges affect vital biotic interactions such as seed dispersal by frugivores is important for better understanding potential mechanisms that drive species coexistence and diversity within a plant community. Here, we investigated how differences between frugivore communities at the forest edge and interior habitats of a diverse tropical rainforest relate to patterns of animal-mediated seed dispersal and early seedling recruitment. We found that the lemur communities across the forest edge-interior gradient in this system showed the highest species richness and variability in body sizes at intermediate distances; the community of birds showed the opposite pattern for species richness. Three large-bodied frugivores, known to be effective dispersers of large seeds, tended to avoid the forest edge. As result, the forest edges received a lower rate of animal-mediated seed dispersal compared to the interior habitats. In addition, we also found that the seeds that were actively dispersed by animals in forest edge habitats were smaller in size than seeds dispersed in the forest interior. This pattern was found despite a similarity in seed size of seasonally fruiting adult trees and shrubs between the two habitats. Despite these differences in dispersal patterns, we did not observe any differences in the rates of seedling recruitment or seedsize distribution of successful recruit species. Our results suggest that a small number of frugivores may act as a potential biotic filter, acting on seed size, for the arrival of certain plant species to edge habitats, but other factors may be more important for driving recruitment patterns, at least in the short term. Further research is needed to better understand the potential long-term impacts of altered dispersal regimes relative to other 
environmental factors on the successional dynamics of edge communities. Our findings are important for understanding potential ecological drivers of tree community changes in forest edges and have implications for conservation management and restoration of large-seeded tree species in disturbed habitats.

Keywords: edge effects, habitat fragmentation, species interaction, seed dispersal, tropical forest, primate

\section{INTRODUCTION}

Human-induced habitat loss, fragmentation, and degradation of forested habitats around the world have resulted in $70 \%$ of the world's forested area existing within $1 \mathrm{~km}$ of a forest edge (Haddad et al., 2015). While there has been a long history of studies examining the influence of edge habitat on forest ecosystems (Ries et al., 2004; Lindenmayer and Fischer, 2007; Ruffell and Didham, 2016), how ecological processes respond to edges remains poorly explored. Understanding processes that affect forest regeneration, such as seed dispersal, is critical for our ability to predict the impacts of forest fragmentation on forest structure and composition (Magrach et al., 2014). It also has implications for designing conservation and management practices for maintaining biodiversity (Camara-Cabrales and Kelty, 2009).

In forest edges, abiotic factors such as reduced soil moisture or increased sunlight exposure can act as an environmental filter by preventing or favoring the establishment of certain plant species (Kraft et al., 2015). Along with these abiotic factors, changes in ecological processes and species interactions such as seed dispersal by animals (zoochory) can also act as a potential filter for plant communities by limiting or increasing seed supply, which will affect the initial template for regeneration and may ultimately affect the patterns of species occurrence and diversity in a local community (George and Bazzaz, 1999; Myers and Harms, 2009; Albert et al., 2015). Differences in abundance and composition of frugivores may differ due to avoidance or attraction to habitat or resource characteristics present on the forest edge (Johns and Skorupa, 1987; Gray et al., 2007; Gomes et al., 2008).

Edge effects (i.e., the impacts of creating edges of forest habitat as a result of fragmentation) have altered the diversity and density of animal communities across many systems. In a global analysis of 1,673 vertebrate species, the abundances of $85 \%$ of species were affected positively or negatively by forest edges (Pfeifer et al., 2017). These effects result from behavioral and physiological tolerances to the environmental conditions, increased hunting, predation pressures, and differences in available resources (Murcia, 1995; Lenz et al., 2014; Haddad et al., 2015; Pfeifer et al., 2017). For example, edge-related variations in the quality of lemur food trees and the pressures associated with predation avoidance have been found to influence lemur density and distribution in a Malagasy dry forest (Lehman et al., 2006a,b). These edge-driven changes in the floral and faunal communities may affect the dynamics of species interactions. For example, the different environmental conditions at the edge may lead to avoidance of or attraction to the area by certain important seeddispersing frugivores, which is likely to impact seed dispersal services and alter the composition of seeds moving toward the forest edge with implications for forest regeneration patterns.

Differences in the composition of frugivores in edge habitat could, therefore, influence the distribution of important plant functional traits, such as the size of plant propagules that are more likely to arrive in the disturbed community (Cordeiro and Howe, 2001; Michalski et al., 2007; Santos et al., 2008; Albert et al., 2015). Thus, in addition to habitat characteristics on the forest edge, altered seed dispersal patterns may contribute, in the long-term, to tree communities that are taxonomically less diverse and have lower phylogenetic and functional diversity than those in interior habitats (Santos et al., 2010; Haddad et al., 2015; Razafindratsima et al., 2018a). While much work has focused on how plant communities differ in forest edge habitat, more empirical work is needed to better understand and link how altered ecological processes such as animal-mediated seed dispersal may contribute to these differences (Murcia, 1995; Farwig et al., 2017; Bovo et al., 2018; Pires et al., 2018; Rehm et al., 2018; González-Castro et al., 2019).

Characterizing how edge effects alter the composition of disperser assemblages and how this may reflect on patterns of seed-dispersal and recruitment may provide important insights into the mechanisms structuring plant communities in forest edges and provide a better understanding of successional processes in disturbed habitats. To address this, we investigated how a frugivore community differed across a gradient from forest edge to the interior in a diverse tropical rainforest in Madagascar. We then examined how these differences may relate to patterns of animal-mediated seed dispersal and early seedling recruitment in forest edge and interior habitats.

We tested the hypothesis that larger frugivores, which often prefer more pristine habitat in many tropical systems (Emer et al., 2018; Messina et al., 2021), would avoid forest edges, reducing overall frugivore diversity, and that smaller-bodied frugivores would be more abundant in edge habitat because of habitat preferences and/or competitive release (Pfeifer et al., 2017; Püttker et al., 2019). If larger-bodied frugivores are less common near edge habitat, we predicted that this would be reflected by an overall smaller size of seeds dispersed by frugivores in edge habitat. We also predicted that differences in the rates or patterns of seed dispersal between habitat types would be reflected in subsequent recruitment patterns.

\section{MATERIALS AND METHODS}

\section{Study Site and Systems}

We carried out this project in a forest managed by local communities in the Andasibe region, within the rainforest Ihofa. 
This forest is part of the Mantadia-Zahamena corridor, located in eastern Madagascar and transversed by the Ihofa River. Its protection is partly overseen by community-based management, but intense anthropogenic pressures (e.g., unmanaged shifting agricultural practices, logging, and hunting) persist. During our study period (January 2017-2018), the field site experienced an average temperature of $19.2^{\circ} \mathrm{C}$ (range: $10.8-34.7^{\circ} \mathrm{C}$ ) and an average monthly rainfall of $76.97 \mathrm{~mm}$ (range: $6-333 \mathrm{~mm}$ ) (Razafindratsima, unpbl.). The forest boundaries or edges, where we set up the transects and plots described below, are characterized by soft edges with a small expanse of successional fields separating the forest from the adjacent small-scale agricultural fields. These fields result from shifting agricultural practice, in which part of the forest is clearcut, burnt, and converted for cultivation. According to local communities, the edges in this study were created between 1990 and 2012; thus, many of the current adult trees at the forest edge may have been remnants from the edge creation. Such a landscape matrix is similar to other forested environments found along Madagascar's eastern biome (Razafindratsima et al., 2018a). Fruiting in the site during our study period occurs year-round with a peak in the number of species fruiting and in the intensity of fruiting in June (Supplementary Appendix 1).

\section{Frugivore Communities}

To characterize the frugivore community of the area, we conducted animal surveys along five linear transects running $3 \mathrm{~km}$ from forest edge to the interior, for a total of 253 days of sampling. These transects were at least $1 \mathrm{~km}$ apart from each other. We surveyed each transect once a week from January to December 2017, for a total of 49-54 sampling days per transect (Supplementary Table 1). Each survey took place either during the day (starting at 05:00 h) or at night (starting at 17:30 h). It took between 2 and $9 \mathrm{~h}$ (for an average of $3 \mathrm{~h}$ and $40 \mathrm{~min}$ ) to complete each survey. Longer sampling time was a result of the difficulty in hiking the steep terrain during or after heavy rains. We conducted our weekly day and night surveys for each transect on two consecutive dates (i.e., 2 days in a row) but alternated between edge and interior where we started the survey of each transect. For example, on a given week, we first started the day survey at the forest edge and then did the night survey starting at the forest interior for the same transect, and these patterns were then alternated for our repeated weekly surveys. For the night surveys, we used LED Flashlights (Maglite ST3D016) to help with the visibility on the trail; whenever we encountered an animal, we used a headlamp with Red LED Light to help identify the species. Walking along the trail at a slow pace and pausing every few steps, a team of 2-3 people looked in every direction for any animal (on trees, on the ground, and in cavities if present). When encountering a vertebrate, we recorded the following standard survey data: time and location of sighting along the transect, identity and number of animals detected, perpendicular distance to the animal sighted from the transect (visual estimation), and animal behavior (Buckland et al., 2010; Brook et al., 2019). If the animal was observed feeding on plants, we recorded the food item (e.g., leaves, fruits, and flowers) and the plant species.
During these surveys, we made 2,096 animal sightings in total, including 60 species of birds, 14 species of lemurs, two species of carnivores, and two species of rodents (details in Supplementary Table 2). We focused the analyses in this article on birds and lemurs because these are the known major taxonomic groups serving as primary seed dispersal agents in Malagasy ecosystems among these encountered taxa (Razafindratsima, 2014; Razafindratsima et al., in press). While the carnivoran species Galidia elegans and the rodent species Nesomys rufus and Eliurus sp. also consume fruits and/or seeds in other systems (Nowak, 2005; Garbutt, 2007; Razafindratsima, 2017; Razafindratsima et al., in press), we did not include them as part of the frugivore community in this study because we observed each species only once during the 1-year-long transect surveys and their ability to disperse seeds is unknown. It is also important to note that fruit bats also play an important role in seed dispersal services in Madagascar (Racey et al., 2010; Andrianaivoarivelo et al., 2012; Razafindratsima et al., in press). They might also be present in our study site given their current geographic distribution (Racey, 2016; Andrianaivoarivelo et al., 2019, 2020). However, we did not encounter any fruit bats during our transect monitoring. The only bat species we saw passing by in a few instances was Miniopterus manavi, an insectivorous species (Rakotoarivelo et al., 2007). The other vertebrate species were either seed predators or are not known to consume or disperse fruits/seeds (Razafindratsima et al., in press).

We assigned each bird/lemur species as being frugivorous if the species is known to consume fruits/seeds and present seed dispersal behavior. Data on these behaviors were based on frugivory observations during the transect sampling, direct and camera-trap observations of animal visitors feeding in fruiting trees in the area (Raoelinjanakolona, unpbl. data), and on data from the literature (Razafindratsima et al., 2018c,d; Razafindratsima et al., in press). Thus, we had 21 species of birds and 11 species of lemurs categorized as frugivores in this study (Supplementary Table 2).

To describe the frugivore community, we determined species richness, encounter rates (number of individuals per sampling effort), and distribution of body masses for encountered frugivores for each $100-\mathrm{m}$ increment along the edge-interior transects (i.e., $0-100 \mathrm{~m}, 101-200 \mathrm{~m}$, etc.). We used quadratic polynomial regression models to investigate how these metrics varied as a function of distance from forest edge for each taxonomic group. Polynomial regressions were used because ecological edge effects are unlikely to be linear with distance from the edge (Murcia, 1995; Lehman et al., 2006a,b) and because it was clear that linear regressions were a poor fit to the data. We ran these models in R (R Core Team, 2020).

We also examined the patterns of encounters for individual species that we expected to be especially important dispersers for large-seeded plant species in the community. We focused specifically on fruit-eating pigeons (Alectroenas madagascariensis and Treron australis) and the large-bodied frugivorous lemurs, Eulemur fulvus, E. rubriventer, and Varecia variegata, because they are known to play an important role as seed dispersers in Madagascar's forested ecosystems (Bollen et al., 2004; Razafindratsima and Dunham, 2015; 
Razafindratsima et al., in press). While the large-sized folivorous lemur species Indri indri and Propithecus diadema also consume fruits and, thus, were considered as part of the larger frugivore community, they are known to masticate and consume large seeds and are likely not important dispersers for large-seeded plants (Dew and Wright, 1998; Powzyk and Mowry, 2003; Semprebon et al., 2004).

We investigated how the frugivore communities differed across the edge-interior gradient in terms of diversity in body mass by characterizing the functional diversity of each community in the $100-\mathrm{m}$ increments. To do that, we calculated the Petchey and Gaston's (2002) functional diversity index, $F D$, a dendrogram-based metric that estimates the dispersal of a community of species in a trait space. We used the R-package pincate (Kembel et al., 2010) to calculate $F D$ values. We also performed quadratic polynomial regressions to determine how the values of $F D$ vary as a function of distance from forest edge for each taxonomic group.

\section{Adult Tree and Shrub Communities}

To better understand how adult tree and shrub communities found in edge and interior forest habitats may be associated with patterns of dispersal and recruitment, we established ten botanical plots of $40 \times 40 \mathrm{~m}$. We set up one plot at the start and end of each transect (five plots in forest edge and five in interior habitats). Within each plot, we identified all trees/shrubs greater than $10 \mathrm{~cm}$ in diameter at breast height $(\mathrm{DBH}$, set at $1.30 \mathrm{~m}$ from the ground). We also tagged these individuals using a numbered aluminum tag nailed to each tree. Local Malagasy field technicians with extensive knowledge of the local flora helped identify the trees to their vernacular names. We determined the scientific names using a database of vernacular species names in the area previously established with expert Malagasy botanists (Razafindratsima, unpbl.). If they could not identify the species in the field, we collected samples of leaves and any reproductive materials present (flowers and fruits) for identification by specialists at the Malagasy National Herbarium at the Parc Botanique et Zoologique de Tsimbazaza (PBZT). Using this dataset, we measured the species richness and density of the adult trees/shrubs in forest edge and interior habitats. We assigned the dispersal mode of each identified plant species as zoochoric or abiotic, based on frugivory and seed dispersal data found in the literature and reported in databases (Razafindratsima et al., 2017; Razafindratsima and Dunham, 2019; Albert-Daviaud et al., 2021), from direct and camera-trapping observations of animal consuming fruits (Raoelinjanakolona, unpbl. data; Nantenaina, unpbl. data), from the observations of seeds found in feces in our seed traps, and from observations of seed and fruit traits. We gathered information on the seed length of each species from these same sources as available. We focused only on seed length as a measure of seed size because it made our data comparable to other studies in Madagascar and other tropical systems (Osuri et al., 2016; Razafindratsima et al., 2018b) and seed length and diameter were strongly correlated in our system (Supplementary Figure 1; $\left.N=79, R^{2}=0.89, p<0.001\right)$.

We analyzed how the habitat edge and interior differed in terms of adult plant species composition, richness, density, and the proportions of zoochoric plant species and individuals. To compare species composition between habitat types, we used a non-parametric permutational multivariate analysis (PERMANOVA) with the R-package vegan (Oksanen et al., 2007) based on Bray-Curtis similarity metrics with 9999 permutations (McArdle and Anderson, 2001). We also examined how the richness, density, and proportions of the species that were actively dispersed by animals during this study (found in seed traps as described below) differed between the two habitat types using linear mixed-effects (LME) regression models with the R-package nlme (Pinheiro et al., 2017). For each LME, we considered each metric as a dependent variable (richness, density, and proportions), habitat type as fixed effect (edge vs. interior) and transect as random effect. We incorporated latitude and longitude into the model to account for potential spatial autocorrelation.

\section{Seed Dispersal Rates}

We sampled animal-mediated seed rain using seed traps, a widely used method in estimating seed rain in other studies (e.g., Razafindratsima and Dunham, 2016; Rogers et al., 2017), from January to December 2017. Each trap was made of a fine-mesh net attached to a flexible wood ring and hung on trees at $1.50 \mathrm{~m}$ high to reduce predation by ground-dwelling rodents that may predate and/or remove the seeds. This set-up is adequate for this study because the birds and lemurs in this system either fly or are arboreal; thus, they are likely to defecate, regurgitate, or drop most of the seeds they consume or handle from above. We used a total of 90 seed traps, placed at regularly spaced points in the square grid plot described above ( 9 traps $\times 5$ plots $\times 2$ habitats). We checked each trap at least once a week, during which we identified, counted, and measured the length of all seeds found in the trap. The timing of trap monitoring varied over time due to some logistical constraints (for example, heavy rain may have prevented the team from getting into the site). To account for these differences, we incorporated the number of days between monitoring into the calculation of seed dispersal rates, which was then defined as the number of animal-dispersed seeds into each trap per $\mathrm{m}^{2}$ per day. Any trap that did not have seeds or fruits in it at a given monitoring day was assigned a value of zero. When needed for accurate identification, and when possible, we compared the seed from the trap with seeds from plants that were fruiting during the vegetation surveys. Additionally, we also relied on the expert knowledge of the local research technicians familiar with the local flora to identify the species based on specific seed characteristics. We focused our analyses of seed dispersal rates on seeds that appeared to have been dispersed by animals (active dispersal), i.e., depulped seed (pericarp removed) still in feces or with some fecal material attached to it, or it was a depulped seed from a species with an animal-dispersal syndrome. We compared how the mean rates of active seed dispersal differed between the two habitat types by performing an LME regression model, in which we considered the habitat type as a fixed effect (edge vs. interior) and transect as a random effect. An initial visualization of the data through boxplot showed some outliers; thus, we used the interquartile range (IQR) criterion (Vinutha et al., 2018) to identify and exclude these outliers in 
the model. We also incorporated in the model the exact location of each trap within the plot grid to account for potential spatial autocorrelations. We examined how the patterns of distribution frequency of seed length varied between the two habitat types by comparing the median of seed length in the two habitat types using a two-sample Wilcoxon test.

In addition to this active dispersal of seeds by animals, we also recorded the dispersal of seeds that were still contained within fruits, and we assumed they were dispersed by abiotic means regardless of dispersal syndrome (defined here as passive dispersal). We considered these dispersal events as passive because they may have reached the traps without assistance from animal dispersers (e.g., falling from nearby adults when ripe, being knocked down by wind). We performed the same statistical analyses as with the active seed dispersal for the passively dispersed seeds.

\section{Seedling Communities}

We examined community structure and early-stage recruitment of seedlings through observations in plots of 10 by $10 \mathrm{~m}$ that we established at a random location within each of the aforementioned botanical plots. Each plot was left open but delimited with inconspicuous material to easily locate it for later monitoring. We identified and counted all seedlings that were between $2 \mathrm{~cm}$ and $100 \mathrm{~cm}$ tall within each plot; we also tagged each individual using a Tyvek water-resistant wristband marked with a waterproof marker. We set up these plots in FebruaryMay 2017 and monitored them in November-December 2018 to check whether each tagged seedling was still alive (approximately 21 months). During the monitoring, we recorded and tagged all newly established seedlings that had reached $2 \mathrm{~cm}$ in height.

Similar to the analysis of the adult plant community, we also analyzed how the habitat edge and interior differed in terms of seedling species composition, richness, and density. To determine differences in species composition, we used a nonparametric permutational multivariate analysis (PERMANOVA) with the R-package vegan (Oksanen et al., 2007) based on BrayCurtis similarity metrics with 9999 permutations (McArdle and Anderson, 2001). We performed linear mixed-effects (LME) regression models to examine statistical differences in seedling species richness and density between the two habitat types. For each LME, we considered habitat type as a fixed effect (edge vs. interior) and transect as a random effect. We also incorporated in the model the latitude and longitude where the plots were located to account for potential spatial autocorrelation.

We examined the linkages between the seedling and adult communities by comparing species richness at both stages with a PERMANOVA and by investigating how the percentages of dispersed seedlings (those without adults of the same species occurring in the same plot) differed between edge and interior habitats using an LME (with habitat type as a fixed effect, transect as random effect and longitude and latitude incorporated to account for potential spatial autocorrelation).

We calculated a recruitment rate for each plot, as follows: $R R=\left(N_{i}-D+E\right) / N_{i}$ in which $N_{i}$ is the initial number of seedlings, $\boldsymbol{D}$ corresponds to the number of seedlings that died, and $\boldsymbol{E}$ represents the number of seedlings that emerged after the initial counting. We analyzed how seedling recruitment differed between the two habitat types by performing an LME, using two types of datasets: (1) only the species found in the seed traps and (2) all the species in the seedling plot. The first one allows us to examine the link between animal-mediated seed dispersal rates and seedling recruitment. The second one considers passive dispersal, given that seeds within fruits may still be able to germinate. In either case, we consider seed species as a random factor because different species may have different recruitment probabilities. We also examined the association between dispersal rates and seedling recruitment using a Pearson correlation test. To test if recruitment of species that we observed being actively dispersed in our study was biased in terms of seed size in either habitat, we ran a generalized linear model in $\mathrm{R}$ ( $\mathrm{R}$ Core Team, 2020), with seed length of the recruited species as the dependent variable and habitat type as the factor.

\section{RESULTS}

\section{Frugivore Community}

Species richness values of birds and lemurs across the edge to interior gradient were not explained by linear relationships, but showed marginally significant or significant fit, respectively, to polynomial (quadratic) regression models. Bird richness showed a weak " $U$ " shaped relationship across the gradient (Figure 1A; $\left.R^{2}=0.04, F_{2,147}=3.12, p=0.05\right)$ while lemurs displayed a humped shaped pattern of species richness with higher richness at intermediate distances (Figure 1A; $R^{2}=0.12, F_{2,147}=9.54$, $p<0.001$ ). The mean encounter rates (number of individuals encountered per sampling efforts) of birds and lemurs showed no relationship to distance to edge habitat (Figure 1B; Birds: $R^{2}=0.01, F_{2,147}=0.15, p=0.86$; Lemurs: $R^{2}=0.03, F_{2,147}=2.45$, $p=0.08)$.

There were also no significant patterns (Figure 1C) regarding the size distribution of fruit-eating birds $\left(R^{2}=0.03, F_{2,147}=2.38\right.$, $p=0.09)$ or lemurs $\left(R^{2}=0.01, F_{2,147}=0.14, p=0.87\right)$ along the edge-interior gradient. Among these fruit-eating species, 11 bird species and 4 lemur species were observed within $100 \mathrm{~m}$ of the forest edge; however, all of them were also found in the interior habitats (Supplementary Table 2). None of the fruit-eating bird species appeared to be edge-specialists, as they were all observed in the interior forest up to $3,000 \mathrm{~m}$ from the edge. With the exception of four species (Eurystomus glaucurus, Coua caerulea, C. reynaudii, and Coracopsis vasa), the bird species found near the edge were small-sized $(<100 \mathrm{~g})$. The site's two frugivorous pigeons, A. madagascariensis and T. australis, may avoid edge habitat as they were absent from forest edges and were only observed at a minimum distance of 475 and $1,529 \mathrm{~m}$ from the edge, respectively (Figure 1C and Supplementary Table 2). None of the encountered lemur species in our study appeared to be edge-specialists; however, one of the three large-bodied ( $>1,500 \mathrm{~g})$, seed-dispersing lemur species, $V$. variegata, was only encountered in the interior, at $\geq 1,829 \mathrm{~m}$ (Supplementary Figure 2). The other two large-bodied, seeddispersing lemur species, E. fulvus and E. rubriventer, were observed both near the edge and in the interior habitats. 


\section{A Species Richness}
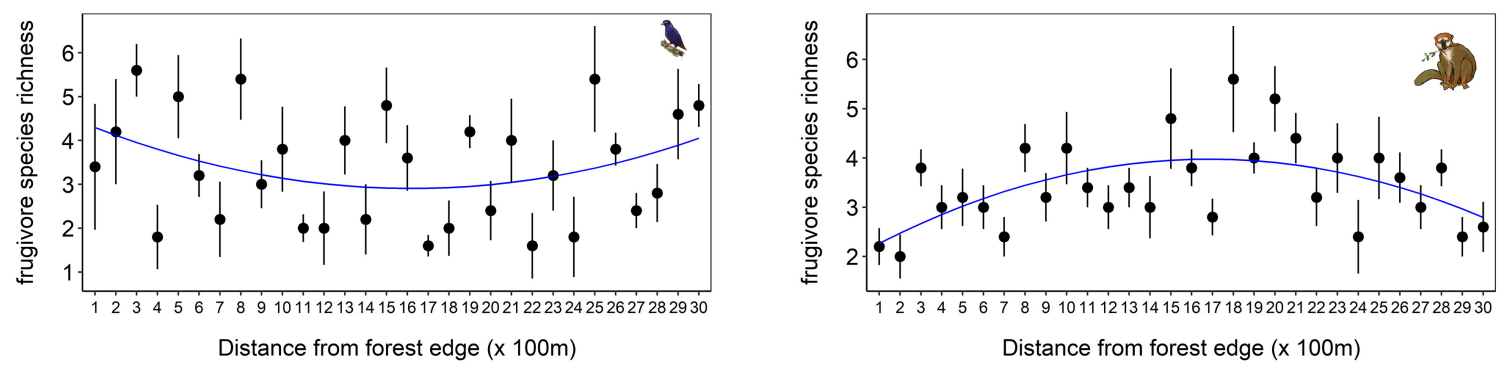

B Encounter rates
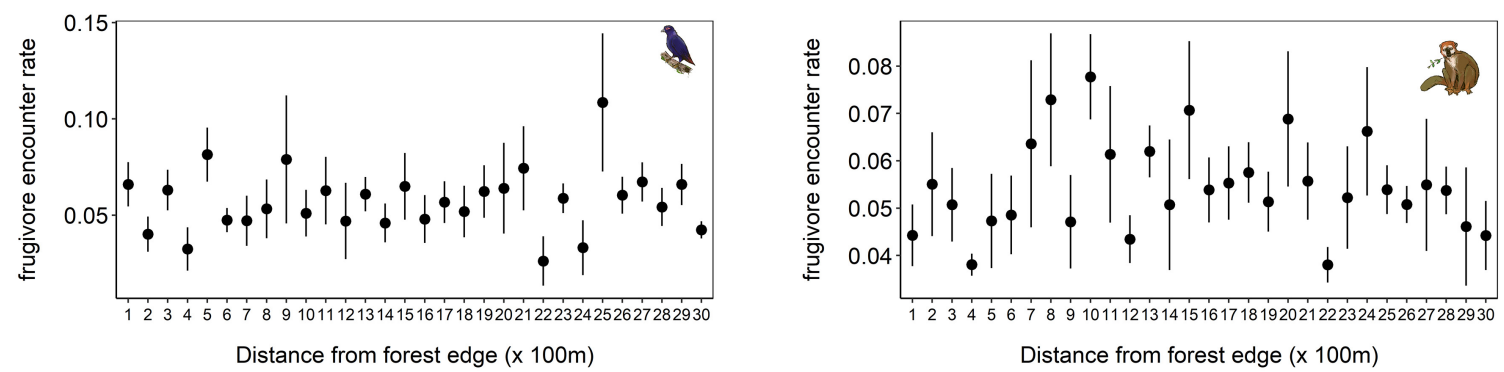

C Body mass
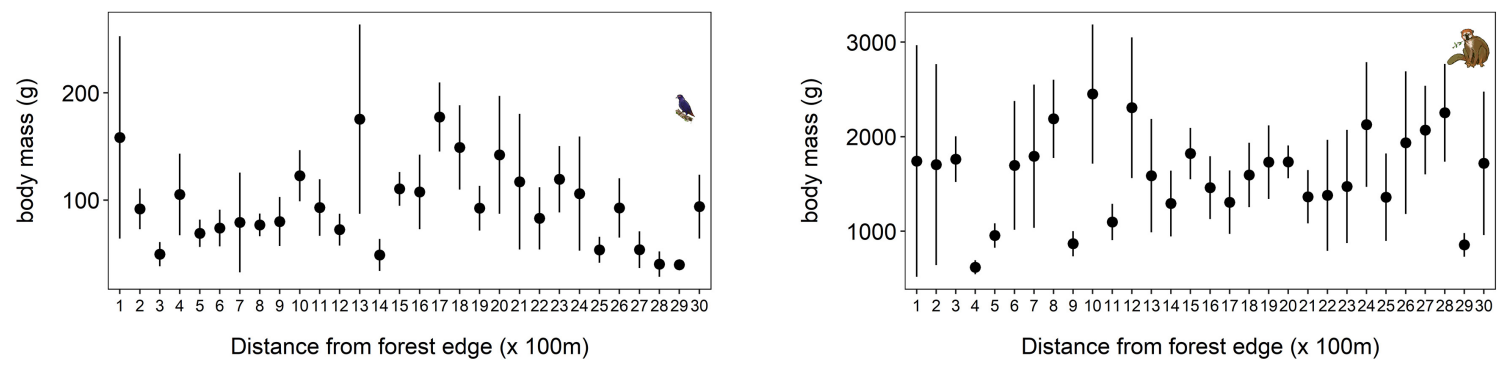

D Functional Diversity
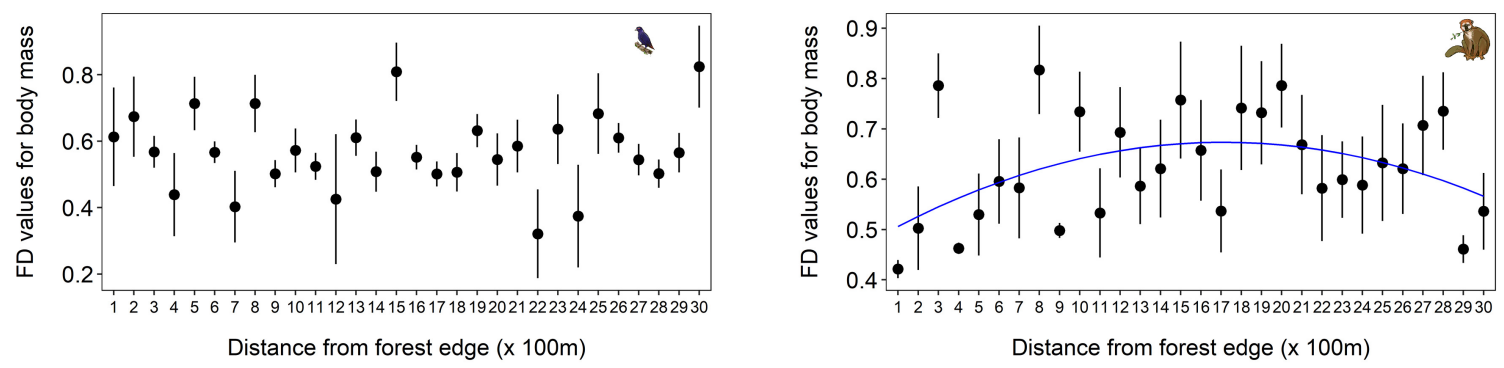

FIGURE 1 | Species richness (A), encounter rates (B), body mass (C), and functional diversity measures of size variation (D) of frugivorous birds (left) and lemurs (right) along an edge-interior gradient in transects of 3,000 m. Circles represent mean values across transects, whiskers indicate standard deviations. The blue line corresponds to the fit of a significant quadratic polynomial regression. Taxa illustrations by Finaritra Randimbiarison.

Our most common lemur encounters at the edge habitat were small-sized omnivorous and folivorous lemurs (Microcebus lehilahytsara and Avahi laniger) and the large-sized folivorous species, Indri indri (Supplementary Table 2).

Functional diversity of size did not show a clear pattern across the habitat gradient for the bird community (Figure 1D;
$\left.R^{2}=0.042, F_{2,27}=0.594, p=0.559\right)$. However, for frugivorous lemurs, functional diversity of body sizes demonstrated a weak hump-shaped curve with the highest values at intermediate distances between habitats, mirroring the pattern of species richness, though the significance of the pattern was only marginal (Figure 1D; $R^{2}=0.194, F_{2,27}=3.265, p=0.053$ ). 


\section{Adult Tree/Shrub Richness and Density}

We sampled tree/shrub communities on the forest edge and interior habitats for comparison. In total, we surveyed 1,305 individual trees and shrubs greater than $10 \mathrm{~cm}$ in diameter $(601$ in forest edge and 704 in interior) of 140 species. The plant species making up the assemblages in the forest edge and interior habitats showed no significant difference in species composition $\left(F_{1,8}=0.85, p=0.65\right)$. In addition, the two habitat types had similar size distributions of adult trees (diameter and height; Supplementary Figure 3). Further, they did not differ in terms of species richness $\left(t_{4}=-0.24 ; p=0.82\right.$; Supplementary Figure 4A) or density $\left(t_{4}=1.49, p=0.21\right.$; Supplementary Figure $\left.4 \mathrm{~B}\right)$.

We found that on average, across plots, a higher percentage of plant species in the interior were zoochoric $(84.93 \%$ at the edge vs. $89.52 \%$ interior); these differences were small but statistically significant $\left(t_{4}=5.02 ; p<0.01\right)$. However, there was no significant difference in the percentage of zoochoric plant individuals between the edge and interior plots $\left(t_{4}=2.20\right.$; $p=0.09 ; 86.60 \%$ zoochoric individuals in the edge vs. $92.28 \%$ in the interior). Additionally, we found that the density of the adult plant individuals of the species that were actively dispersed by animals during this study did not differ between the two habitat types $\left(t_{4}=0.82 ; P=0.45\right)$. These communities of plants also had similar patterns of seed sizes between the edge and interior habitats (Supplementary Figure 5; $t_{48}=-0.46$, $p=0.65$ ).

\section{Seed Dispersal Rates}

The mean rates of active seed dispersal, based on the count of animal-mediated seed rain into the traps, were significantly different between habitat types, with a higher rate reaching the forest interior than the forest edge $\left(t_{77}=2.14, p=0.04\right.$; Figure 2A). The frequency distribution of the length of seeds dispersed by animals appears to be different, with a higher proportion of small seeds dispersed in the forest edge than the interior habitats, which had a higher proportion of mediumsized seeds (Figure 2B). The median length of the seeds in the edge habitats was shorter than that of seeds in the interior habitats $(p<0.0001)$. Nine out of 13 identified species of seeds collected in the seed traps that were actively dispersed in the forest edge were absent from the seed rain observed in the forest interior. In comparison, 15 out of the 19 identified seed species in the interior seed rain were not present in the forest edge (Supplementary Table 3 ).

Seeds dispersed passively (i.e., whole fruits found within the seed rain), accounted for $86.20 \%$ of the total collected propagules in the seed traps. Dispersal rates of passively dispersed seeds in the edge and the interior forest did not differ significantly (average dispersal rates in the edge: 0.07 fruits per $\mathrm{m}^{2}$ per day, interior: 0.08 fruits per $\mathrm{m}^{2}$ per day; $t_{30}=0.41, p=0.68$ ). Regarding the distribution of the size of the fruits in the traps, both edge and interior habitats appear to have a high proportion of small-sized fruits, but the interior forest also received a higher proportion of medium-sized fruits than the forest edges (Supplementary Figure 6). However, these differences were not statistically significant $(p=0.81)$.

\section{Seedling Richness, Density, and Recruitment Dynamics}

The forest edge and interior had significantly different species compositions of seedlings $\left(F_{1,8}=1.75, p=0.04\right)$. However, the seedling communities in these two habitat types did not differ significantly in terms of species richness $\left(t_{4}=1.00 ; p=0.37\right.$; Figure $3 \mathbf{A})$ or density $\left(t_{4}=0.19, p=0.86\right.$; Figure $\left.3 \mathbf{B}\right)$.

Overall, we found significantly different species compositions between the seedling and adult stages $\left(F_{1,18}=6.08, p<0.001\right)$; Some species found at the seedling stage were not present at the adult stage in the same habitat type but were potentially actively dispersed (Supplementary Table 5). At the edge habitats, we estimated that an average of $60.99 \%$ of seedling species, did not have the same species of adults in the plot where they occurred; whereas in the forest interior, it was the case for $67.76 \%$ of the seedling species. These differences, however, were not significantly different $\left(t_{4}=1.66, p=0.17\right)$.

When we looked only at species that were also found in seed traps, we did not find a significant difference in seedling recruitment $\left(t_{136}=-0.15, p=0.88\right.$; Figure $\left.3 \mathrm{C}\right)$ between the two habitat types. There was also no significant difference found when all the seedlings in the plot were considered in the analysis, i.e., both passive and active seed rain (seedling recruitment: $t_{159}=0.52, p=0.60 ;$ Supplementary Figure 7). We found that the rates of seedling recruitment were not associated with the rates of seed dispersal, neither for actively dispersed seed species found in the traps $\left(t_{8}=-0.13, p=0.29\right)$ nor when all the seedling species were considered $\left(t_{8}=-0.09, p=0.93\right)$. We also found no bias in seedling recruitment of animal-dispersed species between the two habitat types in terms of seed size of the plant species recruiting over the 21 months of study $\left(t_{102}=-0.542, p=0.589\right)$.

\section{DISCUSSION}

Edge habitats are pervasive around the world as deforestation and fragmentation of forested ecosystems continue to intensify through human activities (Murcia, 1995; Haddad et al., 2015). Understanding how forest edges affect ecosystem processes such as seed dispersal is critical for better understanding potential mechanisms driving plant community differences in edge habitats (Magrach et al., 2014). In our study of Madagascar's eastern rainforest, one of the most biodiverse and endangered forest ecosystems in the world, we found, as predicted, that the seeds reaching edge habitat through dispersal by frugivores were smaller in size than those dispersed in the interior despite no difference in seed size distributions of the adult plant communities. While fruit-eating primate and bird species were not, on average, smaller near the edge habitat, one lemur and two bird species that are known to be effective dispersers of large seeds were not observed near the forest edge. Such findings suggest that a small number of frugivores may act as a potential biotic filter for incoming dispersal of plant propagules. While seedling recruitment overall was not affected in terms of rates or seedsize distribution of successful recruits, long-term suppression of dispersal of some species could ultimately affect community regeneration patterns. Results suggest that active management 

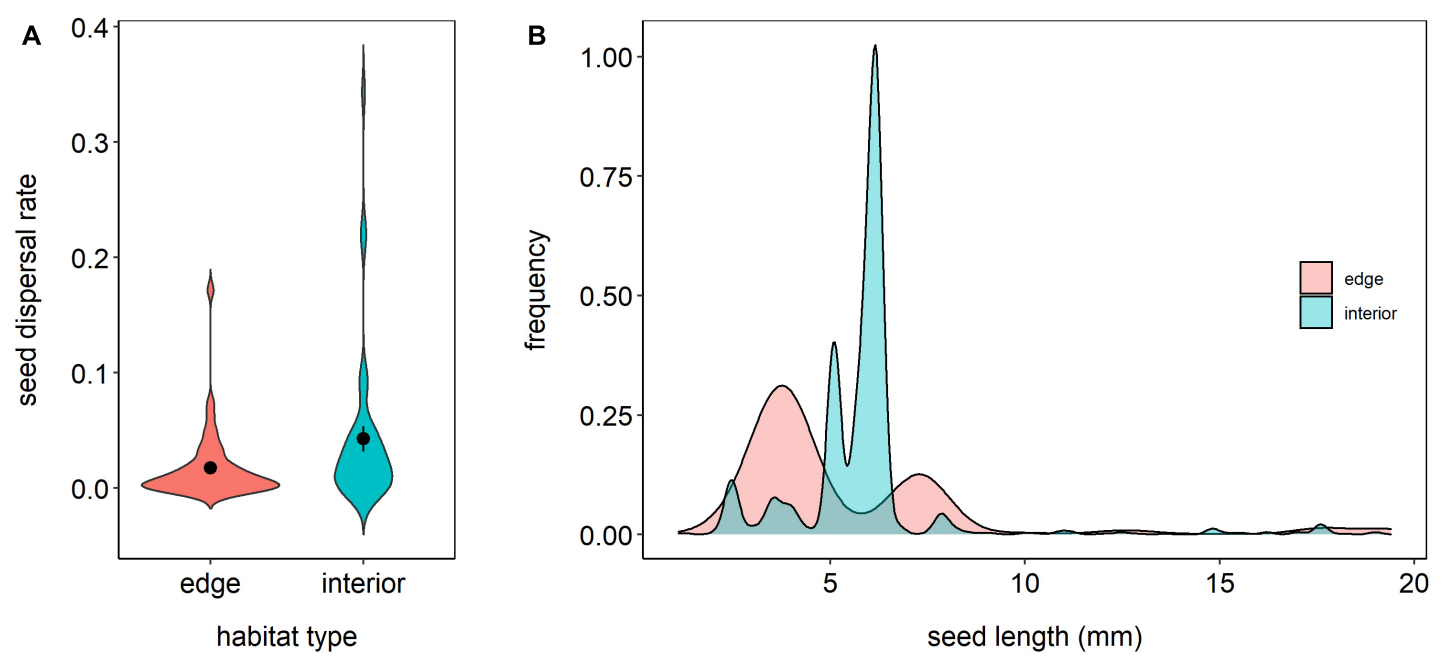

FIGURE 2 | Rates of animal-mediated seed dispersal (A) and size distribution of the animal-dispersed seeds (B) in forest edge and interior habitats.
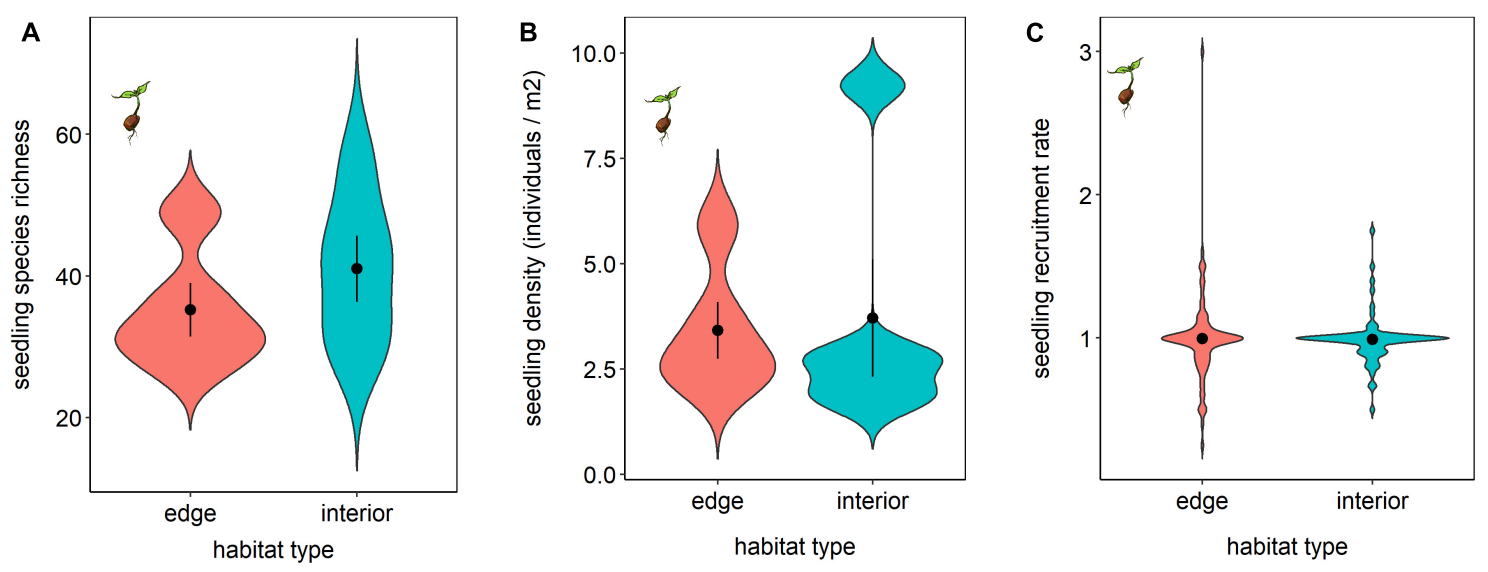

FIGURE 3 | Species richness (A) and density (B) of seedlings as well as rates of seedling recruitment after 21 months (C), for the zoochoric species that were captured in seed traps, in forest edge and interior habitats.

might be necessary to maintain, restore and manage rare largeseeded tree species in fragmented habitats. These findings also highlight the complexity of animal-mediated seed dispersal as a determinant of plant diversity.

The lemur frugivore communities across the forest edge to the interior gradient in this system showed the highest species richness and variability in body sizes at intermediate distances. These patterns may be a result of the variable preferences and tolerance levels of animal species to the environmental conditions across the gradient (Murcia, 1995; Haddad et al., 2015). While our data is inconclusive, intermediate distances may harbor the highest diversity in species and body sizes because it may be frequented by species preferring either edge or interior habitats as well as generalist species.

While we did not find an overall association of larger frugivore body size with distance to the edge habitat as we expected, our seed dispersal data suggests that the most effective dispersers of large seeds in this system may be reduced or missing in edge habitat. Indeed, the forest edge in our study site was not frequented by the most frugivorous large-bodied lemur species in this system, Varecia variegata, which is one of the most important seed dispersers for large-seeded tree species in many of Madagascar's ecosystems (review in Razafindratsima et al., in press), nor by the two fruit-eating pigeons known to swallow large seeds (Supplementary Table 2). In contrast, the edge habitat is frequented by small-sized omnivorous and folivorous lemurs (such as Microcebus and Avahi) and by the large-sized folivorous Indri indri (Supplementary Table 2). Species within the genera Microcebus and Avahi have been found to have a flexible diet and high tolerance to different types of forest, such as disturbed habitats (Rendigs et al., 2003; Murphy et al., 2016; Knoop et al., 2018; Ramananjato et al., 2020; Ramananjato and Razafindratsima, 2021), and they are frequently observed to forage in forest edge habitats. Primate species that have a high proportion of leaves in their diet, such as Indri indri, are also often less vulnerable to habitat disturbance 
than species with a diet dominated by fruits because of the relatively high density and quality of foliage that is often available in disturbed habitats (Glessner and Britt, 2005; Irwin et al., 2010; Seaman et al., 2018).

Many of the bird species in this study site also seem to avoid the forest edge, as only $30 \%$ of all the encountered bird species $(n=60)$ were observed in the forest edge, and none of them were edge-specialists (Supplementary Table 2). Of the frugivorous birds, only 11 out of 21 species were observed in the edge habitat. As with lemurs, a majority of the large-sized frugivorous bird species, such as fruit-eating pigeons (T. australis and A. madagascariensis) and a frugivorous coua ( $C$. serriana), may be interior specialists as they were absent from forest edges. The absence of these species in forest edges in Madagascar may have consequences for the many plants that specialize in bird dispersal in Madagascar's diverse rainforests (Rakotomanana et al., 2003; Razafindratsima, 2014). These results also suggest forest fragmentation may be an important threat to some frugivore bird populations in Madagascar where increasing and extensive habitat disturbance and fragmentation of forested habitat (Harper et al., 2007; Vieilledent et al., 2018) may limit their populations. These results were surprising, in part because none of the frugivorous birds are currently listed as threatened by the IUCN Red List (IUCN, 2021); however, further research and assessment may be necessary.

These differences in frugivores visiting edge vs. interior forests were associated with different rates of animal-mediated seed dispersal, estimated from the seed rain, between the two habitat types. The forest edge received a lower rate of animal-mediated seed dispersal than the interior habitats. The reduced number of large and highly frugivorous animals in edge habitats has been suggested to drive the lower seed dispersal rates in edge habitats in other systems (Magrach et al., 2014).

The median size of seeds reaching the forest edge habitat through dispersal by animals was smaller than those dispersed into the forest interior. Edge habitats had a higher proportion of small seeds than interior habitats, which had a higher proportion of medium-sized seeds. This result corroborates findings in other systems, showing a higher percentage of medium, large, and very large seeds in the seed rain received by forest interior than forest edge habitats (Oliveira et al., 2004; de Melo et al., 2006). This pattern of endozoochorous seed dispersal we observed was unlikely to be a result of the distribution of seasonally fruiting trees on the edge vs. interior forest because we found no significant difference in the number of these trees between habitat types. However, future work should also consider fruit crop size, which may vary between habitat types because of differences in abiotic conditions that may influence fruit production (Restrepo et al., 1999; Dunham et al., 2018; Gonçalves da Silva et al., 2018). We also found that seeds of several plant species were only actively dispersed by animals in one or the other habitat, which may reflect the differences in frugivore species composition between the edge and interior habitat.

Despite the bias in size distributions of seeds falling in edge and interior forests, the rate of seedling recruitment of animal dispersed plants did not differ overall, and there was no bias in recruitment of small-sized plant species on the edge habitat. It is also possible that historical seed bank composition (Klanderud et al., 2010) and other ecological processes, such as competition or alteration of the seed bank through secondary dispersal and/or seed predation (Dausmann et al., 2008; Razafindratsima, 2017), may have important influences on patterns of recruitment (Eriksson, 1995; Eriksson and Eriksson, 1997; Wenny, 2000). For example, research in the Amazonian rainforest has shown that tree seedling recruitment in cleared habitat is less likely to originate from seed rain than from the seed bank (Young et al., 1987; Lawton and Putz, 1988), most likely due to the high rates of seed predation of newly fallen seeds by animals (Uhl, 1987). Regardless of the mechanism, these findings support the general concept that although seed species supply through dispersal is important, it is not sufficient on its own to structure plant communities; it interacts with local environmental conditions (Myers and Harms, 2009). Further, we also suspect that the short duration of this study may have limited our ability to detect significant impacts or even to differentiate the existence of competitive exclusion from environmental filtering.

While we found no differences in recruitment patterns in our study, further work should examine how biases in dispersal patterns may translate into differences in seed bank compositions and successional impacts in forest edges over longer time scales. Size-biased patterns of seed rain may influence the successional dynamics of plant communities in forest edges over time because these patterns may create opportunities for some species with particular traits to become more prevalent in the edge community (Brodie and Aslan, 2012; Kurten et al., 2015). Seed rain also may influence the composition of the seed bank for future recruitment (Wandrag et al., 2015). The forest edge habitat could become dominated by small-seeded pioneer plants, lose rare tree species, and become homogeneous in terms of floristic composition over time (Oliveira et al., 2004; Melo et al., 2010; Lôbo et al., 2011). Small seed size is also associated with lower aboveground carbon storage in trees in this region (Razafindratsima et al., 2018b); thus, future succession of edges toward fast-growing species with smaller seed sizes could result in a large-scale reduction of carbon storage from fragmented forests. It is also possible that the differences in the biotic processes and abiotic environment in edge habitat may outweigh any impacts that more subtle differences in seed rain may have (Balcomb and Chapman, 2003; Orrock et al., 2006). Further studies examining the role of seed dispersal limitation on the dynamics and biodiversity of tree communities in edge habitats may help resolve this.

\section{Conservation and Management Implications}

If seed supply is limiting for forest edge communities, management of large-seeded species may need to be considered in some areas. For example, encouraging key seed dispersers to frequent the edge habitats could be useful for conserving rare, large-seeded species and increasing plant diversity in these 
areas (Couvreur et al., 2004; Cosyns et al., 2005; Chapman and Dunham, 2018). Generalist seed dispersers could increase the odds of many species reaching and establishing in these areas, thereby increasing local species richness (Myers and Harms, 2009; McConkey et al., 2012; Carlo and Morales, 2016). This is especially important to consider in current human-modified landscapes, as land-use transformations pose critical concerns for a large number of plant populations worldwide (Murcia, 1995; Tylianakis et al., 2008; Haddad et al., 2015), and particularly in the tropical forests of Madagascar (Harper et al., 2007; Razafindratsima et al., 2018a; Morelli et al., 2020). Plus, in the long-term, if not properly managed, the forest edge could recede into the core of the forest, affecting forest regeneration and succession (Gascon et al., 2000). Encouraging seed dispersal into these habitats could be possible by increasing the attraction of animal frugivores to visit them - for example, by planting specific food trees and/or installing human-made perching structures (Wunderle, 1997; Martinez and Razafindratsima, 2014; Mantia et al., 2019).

\section{DATA AVAILABILITY STATEMENT}

The raw data supporting the conclusions of this article will be made available by the authors, without undue reservation.

\section{AUTHOR CONTRIBUTIONS}

OR conceived the idea, designed the project, analyzed the data, and drafted the first version of the manuscript, with inputs from AD. OR, NR, RH, RN, and TR collected the data. All authors made revisions in the writing.

\section{FUNDING}

This fieldwork was supported by funding from the American Philosophical Society (Franklin Research Grant), the National Geographic Society (\#9881-16), Harvard University Herbaria, Hrdy Fellowship, and

\section{REFERENCES}

Albert, A., Auffret, A. G., Cosyns, E., Cousins, S. A. O., D’hondt, B., Eichberg, C., et al. (2015). Seed dispersal by ungulates as an ecological filter: a trait-based meta-analysis. Oikos 124, 1109-1120. doi: 10.1111/oik.02512

Albert-Daviaud, A., Perillo, S., and Stuppy, W. (2021). Data from: Seed Dispersal Syndromes in the Madagascan Flora: the Unusual Importance of Primates. Dryad, doi: 10.5061/dryad.dt940

Andrianaivoarivelo, A., Petit, E. J., Razafindrakoto, N., and Racey, P. A. (2012). Alimentation et dispersion de graines chez Rousettus madagascariens G. Grandidier 1928, dans le Nord-Ouest de Madagascar. Revue Ecologie 67, 179191.

Andrianaivoarivelo, R., Andriafidison, D., Cardiff, S. G., Goodman, S. M., Hutson, A. M., Jenkins, R. K. B., et al. (2020). Eidolon dupreanum. IUCN Red List of Threatened Species, e.T7083A22027891.

Andrianaivoarivelo, R., Andriafidison, D., and Razafimanahaka, J. H. (2019). Rousettus madagascariensis. IUCN Red List of Threatened Species, e.T19750A22002909. the College of Charleston (Research and Development departmental funding) to OR.

\section{ACKNOWLEDGMENTS}

We thank the "Ministère de l'Environnement et du Developpement Durable" in Madagascar for research permission (permit $\mathrm{N}^{\circ}$ 291/16/MEEF/SG/DSAP/SCB and 190/17/MEEF/SG/DSAP/SCB.Re). We also thank Rainer Dolch, Alain Alimarisy, Sylvie Andriambololonera, Lantoarisoa Faranirina, Zafimahery Rakotomalala, Jacques Rakotoarisoa, and Tahiana Rakotondrainibe for logistical supports, and the elders of the surrounding villages and the community-based management association VOI FITAMA for permitting us to work in their forest. We are grateful to Jean Rafalimandimby, Jerome Rolland, Joseph Randrianantenaina, Tovo Randrianantenaina, Evangeliste Randrianantenaina, Gerdaya Ratonganirina, Justin Randriamandimby, and Abel Manampisoa for sharing with us their indigenous knowledge of the plants and animals in the region and for their valuable help with data collection. We are also grateful to Mad Randrianasolo and Anjaratiana Tafitamahandry at Association Mitsinjo, Benja Rakotonirina at the Institut Malgache de Recherches Appliquées (IMRA), and the botanists at the Malagasy National Herbarium at the Parc Botanique et Zoologique de Tsimbazaza (PBZT) and MBG Madagascar for their significant help with plant species identification. Special thanks to Angelo Andrianiaina, Veronarindra Ramananjato, Mahandry Andrianarisoa, Solofo Andrianarimalala, Herilanto Ramaroson, Mihajatiana Raoelison, and Hajatiana Rabarison for helping with data collection, Tomás Carlo and Colin Chapman for their insights in the conception of this project, Finaritra Randimbiarison for the illustrations, and Haldre Rogers and two reviewers for their feedback that improved an earlier version of this manuscript.

\section{SUPPLEMENTARY MATERIAL}

The Supplementary Material for this article can be found online at: https://www.frontiersin.org/articles/10.3389/fevo.2021. 655441/full\#supplementary-material

Balcomb, S. R., and Chapman, C. A. (2003). Bridging the gap: influence of seed deposition on seedling recruitment in a primate-tree interaction. Ecol. Monogr. 73, 625-642. doi: 10.1890/02-4036

Bollen, A., Van Elsacker, L., and Ganzhorn, J. U. (2004). Tree dispersal strategies in the littoral forest of Sainte Luce (SE-Madagascar). Oecologia 139, 604-616.

Bovo, A. A. A., Ferraz, K. M. P. M. B., Magioli, M., Alexandrino, E. R., Hasui, É, Ribeiro, M. C., et al. (2018). Habitat fragmentation narrows the distribution of avian functional traits associated with seed dispersal in tropical forest. Perspect. Ecol. Conserv. 16, 90-96. doi: 10.1016/j.pecon.2018.03.004

Brodie, J. F., and Aslan, C. E. (2012). Halting regime shifts in floristically intact tropical forests deprived of their frugivores. Restoration Ecology 20, 153-157. doi: 10.1111/j.1526-100X.2011.00833.X

Brook, C. E., Herrera, J. P., Borgerson, C., Fuller, E. C., Andriamahazoarivosoa, P., Rasolofoniaina, B. R., et al. (2019). Population viability and harvest sustainability for Madagascar lemurs. Conserv. Biol. 33, 99-111.

Buckland, S. T., Plumptre, A. J., Thomas, L., and Rexstad, E. A. (2010). Line transect sampling of primates: can animal-to-observer distance methods work? Int. J. Primatol. 31, 485-499. 
Camara-Cabrales, L., and Kelty, M. J. (2009). Seed dispersal of big-leaf mahogany (Swietenia macrophylla) and its role in natural forest management in the Yucatán Peninsula, Mexico. J. Trop. For. Sci. 21, 235-245.

Carlo, T. A., and Morales, J. M. (2016). Generalist birds promote tropical forest regeneration and increase plant diversity via rare-biased seed dispersal. Ecology 97, 1819-1831.

Chapman, C. A., and Dunham, A. E. (2018). Primate seed dispersal and forest restoration: an African perspective for a brighter future. Int. J. Primatol. 39, $427-442$.

Cordeiro, N. J., and Howe, H. F. (2001). Low recruitment of trees dispersed by animals in African forest fragments. Conserv. Biol. 15, 1733-1741. doi: 10.1046/ j.1523-1739.2001.99579.x

Cosyns, E., Claerbout, S., Lamoot, I., and Hoffmann, M. (2005). Endozoochorous seed dispersal by cattle and horse in a spatially heterogeneous landscape. Plant Ecol. 178, 149-162. doi: 10.1007/s11258-004-2846-3

Couvreur, M., Christiaen, B., Verheyen, K., and Hermy, M. (2004). Large herbivores as mobile links between isolated nature reserves through adhesive seed dispersal. Appl. Veg. Sci. 7, 229-236. doi: 10.1111/j.1654-109X.2004. tb00614.x

Dausmann, K. H., Glos, J., Linsenmair, K. E., and Ganzhorn, J. U. (2008). Improved recruitment of a lemur-dispersed tree in Malagasy dry forests after the demise of vertebrates in forest fragments. Oecologia 157, 307-316. doi: 10.1007/s00442008-1070-6

de Melo, F. P. L., Dirzo, R., and Tabarelli, M. (2006). Biased seed rain in forest edges: evidence from the Brazilian Atlantic forest. Biol. Conserv. 132, 50-60. doi: 10.1016/j.biocon.2006.03.015

Dew, J. L., and Wright, P. (1998). Frugivory and seed dispersal by four species of primates in Madagascar's eastern rain forest. Biotropica 30, 425-437. doi: 10.1111/j.1744-7429.1998.tb00076.x

Dunham, A. E., Razafindratsima, O. H., Rakotonirina, P., and Wright, P. C. (2018). Fruiting phenology is linked to rainfall variability in a tropical rain forest. Biotropica 50, 396-404. doi: 10.1111/btp.12564

Emer, C., Galetti, M., Pizo, M. A., Guimaraes, P. R. Jr., Moraes, S., Piratelli, A., et al. (2018). Seed-dispersal interactions in fragmented landscapes-a metanetwork approach. Ecol. Lett. 21, 484-493.

Eriksson, А̊, and Eriksson, O. (1997). Seedling recruitment in semi-natural pastures: the effects of disturbance, seed size, phenology and seed bank. Nord. J. Bot. 17, 469-482.

Eriksson, O. (1995). Seedling recruitment in deciduous forest herbs: the effects of litter, soil chemistry and seed bank. Flora 190, 65-70. doi: 10.1016/S03672530(17)30626-6

Farwig, N., Schabo, D. G., and Albrecht, J. (2017). Trait-associated loss of frugivores in fragmented forest does not affect seed removal rates. J. Ecol. 105, 20-28. doi: 10.1111/1365-2745.12669

Garbutt, N. (2007). Mammals of Madagascar: A Complete Guide. New Haven, CT: Yale University Press.

Gascon, C., Williamson, G. B., and da Fonseca, G. A. B. (2000). Receding forest edges and vanishing reserves. Science 288, 1356-1358.

George, L. O., and Bazzaz, F. A. (1999). The fern understory as an ecological filter: emergence and establishment of canopy-tree seedlings. Ecology 80, 833-845.

Glessner, K. D., and Britt, A. (2005). Population density and home range size of Indri indri in a protected low altitude rain forest. Int. J. Primatol. 26, 855-872.

Gomes, L. G., Oostra, V., Nijman, V., Cleef, A. M., and Kappelle, M. (2008). Tolerance of frugivorous birds to habitat disturbance in a tropical cloud forest. Biol. Conserv. 141, 860-871.

Gonçalves da Silva, B., Koch, I., and Rodrigues Silva, W. (2018). Fruit production along roads and footpaths in an Atlantic rain forest area. Plant Ecol. Divers. 11, 41-53. doi: 10.1080/17550874.2018.1461268

González-Castro, A., Yang, S., and Carlo, T. A. (2019). How does avian seed dispersal shape the structure of early successional tropical forests? Funct. Ecol. 33, 229-238. doi: 10.1111/1365-2435.13250

Gray, M. A., Baldauf, S. L., Mayhew, P. J., and Hill, J. K. (2007). The response of avian feeding guilds to tropical forest disturbance. Conserv. Biol. 21, 133-141.

Haddad, N. M., Brudvig, L. A., Clobert, J., Davies, K. F., Gonzalez, A., Holt, R. D., et al. (2015). Habitat fragmentation and its lasting impact on Earth's ecosystems. Sci. Adv. 1:e1500052. doi: 10.1126/sciadv.1500052

Harper, G. J., Steininger, M. K., Tucker, C. J., Juhn, D., and Hawkins, F. (2007). Fifty years of deforestation and forest fragmentation in Madagascar. Environ. Conserv. 34, 325-333. doi: 10.1017/S0376892907004262
IUCN (2021). The IUCN Red List of Threatened Species. Version 2021-1. Available online at: https://www.iucnredlist.org

Irwin, M. T., Wright, P. C., Birkinshaw, C., Fisher, B. L., Gardner, C. J., Glos, J., et al. (2010). Patterns of species change in anthropogenically disturbed forests of Madagascar. Biol. Conserv. 143, 2351-2362.

Johns, A. D., and Skorupa, J. P. (1987). Responses of rain-forest primates to habitat disturbance: a review. Int. J. Primatol. 8, 157-191. doi: 10.1007/BF02735162

Kembel, S. W., Cowan, P. D., Helmus, M. R., Cornwell, W. K., Morlon, H., Ackerly, D. D., et al. (2010). Picante: R tools for integrating phylogenies and ecology. Bioinformatics 26, 1463-1464. doi: 10.1093/bioinformatics/btq166

Klanderud, K., Mbolatiana, H. Z. H., Vololomboahangy, M. N., Radimbison, M. A., Roger, E., Totland, Ø, et al. (2010). Recovery of plant species richness and composition after slash-and-burn agriculture in a tropical rainforest in Madagascar. Biodivers. Conserv. 19:187.

Knoop, S., Chikhi, L., and Salmona, J. (2018). Mouse lemurs' use of degraded habitat: a review of the literature. Lemur News 21, 20-31. doi: $10.1101 / 216382$

Kraft, N. J. B., Adler, P. B., Godoy, O., James, E. C., Fuller, S., and Levine, J. M. (2015). Community assembly, coexistence and the environmental filtering metaphor. Funct. Ecol. 29, 592-599. doi: 10.1111/1365-2435.12345

Kurten, E. L., Wright, S. J., and Carson, W. P. (2015). Hunting alters seedling functional trait composition in a Neotropical forest. Ecology 96, 1923-1932.

Lawton, R. O., and Putz, F. E. (1988). Natural disturbance and gap-phase regeneration in a wind-exposed tropical cloud forest. Ecology 69, 764-777.

Lehman, S. M., Rajaonson, A., and Day, S. (2006a). Edge effects and their influence on lemur density and distribution in southeast Madagascar. Am. J. Phys. Anthropol. 129, 232-241.

Lehman, S. M., Rajaonson, A., and Day, S. (2006b). Edge effects on the density of Cheirogaleus major. Int. J. Primatol. 27, 1569-1588. doi: 10.1007/s10764-0069099-z

Lenz, B. B., Jack, K. M., and Spironello, W. R. (2014). Edge effects in the primate community of the biological dynamics of forest fragments project, Amazonas, Brazil. Am. J. Phys. Anthropol. 155, 436-446.

Lindenmayer, D. B., and Fischer, J. (2007). "Edge effects," in Managing and Designing Landscapes for Conservation: Moving from Perspectives to Principles, 165.

Lôbo, D., Leão, T., Melo, F. P., Santos, A. M., and Tabarelli, M. (2011). Forest fragmentation drives Atlantic forest of northeastern Brazil to biotic homogenization. Divers. Distrib. 17, 287-296.

Magrach, A., Laurance, W. F., Larrinaga, A. R., and Santamaria, L. (2014). Metaanalysis of the effects of forest fragmentation on interspecific interactions. Conserv. Biol. 28, 1342-1348.

Mantia, T. L., Rühl, J., Massa, B., Pipitone, S., Verde, G. L., and Bueno, R. S. (2019). Vertebrate-mediated seed rain and artificial perches contribute to overcome seed dispersal limitation in a Mediterranean old field. Restor. Ecol. 27, 13931400. doi: 10.1111/rec.13009

Martinez, B. T., and Razafindratsima, O. H. (2014). Frugivory and seed dispersal patterns of the red-ruffed lemur, Varecia rubra, at a forest restoration site in Masoala National Park, Madagascar. Folia Primatol. 85, 228-243.

McArdle, B. H., and Anderson, M. J. (2001). Fitting multivariate models to community data: a comment on distance-based redundancy analysis. Ecology 82, 290-297.

McConkey, K. R., Prasad, S., Corlett, R. T., Campos-Arceiz, A., Brodie, J. F., Rogers, H., et al. (2012). Seed dispersal in changing landscapes. Biol. Conserv. 146, 1-13. doi: 10.1016/j.biocon.2011.09.018

Melo, F. P., Martínez-Salas, E., Benítez-Malvido, J., and Ceballos, G. (2010). Forest fragmentation reduces recruitment of large-seeded tree species in a semi-deciduous tropical forest of southern Mexico. J. Trop. Ecol. 26, 35-43.

Messina, S., Costantini, D., Tomassi, S., Cosset, C. C., Benedick, S., Eens, M., et al. (2021). Selective logging reduces body size in omnivorous and frugivorous tropical forest birds. Biol. Conserv. 256:109036.

Michalski, F., Nishi, I., and Peres, C. A. (2007). Disturbance-mediated drift in tree functional groups in Amazonian forest fragments. Biotropica 39, 691-701.

Morelli, T. L., Smith, A. B., Mancini, A. N., Balko, E. A., Borgerson, C., Dolch, R., et al. (2020). The fate of Madagascar's rainforest habitat. Nat. Clim. Chang. 10, 89-96. doi: 10.1038/s41558-019-0647-x

Murcia, C. (1995). Edge effects in fragmented forests: implications for conservation. Trends Ecol. Evol. 10, 58-62. 
Murphy, A. J., Farris, Z. J., Karpanty, S., Ratelolahy, F., and Kelly, M. J. (2016). Estimating encounter rates and densities of three lemur species in northeastern Madagascar. Int. J. Primatol. 37, 371-389.

Myers, J. A., and Harms, K. E. (2009). Seed arrival, ecological filters, and plant species richness: a meta-analysis. Ecol. Lett. 12, 1250-1260.

Nowak, R. M. (2005). Walker's Carnivores of the World. Baltimore: JHU Press.

Oksanen, J., Kindt, R., Legendre, P., O’Hara, B., Stevens, M. H. H., Oksanen, M. J., et al. (2007). The Vegan Package. Community Ecology Package 10.

Oliveira, M. A., Grillo, A. S., and Tabarelli, M. (2004). Forest edge in the Brazilian Atlantic forest: drastic changes in tree species assemblages. Oryx 38, 389-394.

Orrock, J. L., Levey, D. J., Danielson, B. J., and Damschen, E. I. (2006). Seed predation, not seed dispersal, explains the landscape-level abundance of an early-successional plant. J. Ecol. 94, 838-845. doi: 10.1111/j.1365-2745.2006. 01125.x

Osuri, A. M., Ratnam, J., Varma, V., Alvarez-Loayza, P., Hurtado Astaiza, J., Bradford, M., et al. (2016). Contrasting effects of defaunation on aboveground carbon storage across the global tropics. Nat. Commun. 7:11351. doi: 10.1038/ ncomms 11351

Petchey, O. L., and Gaston, K. J. (2002). Functional diversity (FD), species richness and community composition. Ecol. Lett. 5, 402-411.

Pfeifer, M., Lefebvre, V., Peres, C. A., Banks-Leite, C., Wearn, O. R., Marsh, C. J., et al. (2017). Creation of forest edges has a global impact on forest vertebrates. Nature 551, 187-191.

Pinheiro, J., Bates, D., DebRoy, S., Sarkar, D., Heisterkamp, S., Van Willigen, B., et al. (2017). Package 'nlme.' Linear and Nonlinear Mixed Effects Models, version, $3-1$.

Pires, L. P., Gonçalves, V. F., Ferreira, G. Â, Camelo, F. R. B., and Melo, C. (2018). Fruit colour and edge effects poorly explains frugivorous bird-plant interactions in disturbed semideciduous forests. Acta Sci. Biol. Sci. 40:40041. doi: 10.4025/actascibiolsci.v40i1.40041

Powzyk, J. A., and Mowry, C. B. (2003). Dietary and feeding differences between sympatric Propithecus diadema diadema and Indri indri. Int. J. Primatol. 24, 1143-1162.

Püttker, T., Barros, C. S., Pinotti, B. T., Bueno, A. A., and Pardini, R. (2019). Cooccurrence patterns of rodents at multiple spatial scales: competitive release of generalists following habitat loss? J. Mammal. 100, 1229-1242.

R Core Team (2020). R: A Language and Environment for Statistical Computing. Vienna: R Foundation for Statistical Computing.

Racey, P. A. (2016). Pteropus rufus. IUCN Red List of Threatened Species, e.T18756A22087230.

Racey, P. A., Goodman, S. M., and Jenkins, R. K. (2010). "The ecology and conservation of Malagasy bats," in Islands Bats: Evolution, Ecology, and Conservation, eds T. H. Fleming and P. A. Racey (Chicago: Chicago University Press), 369-404.

Rakotoarivelo, A. A., Ranaivoson, N., Ramilijaona, O. R., Kofoky, A. F., Racey, P. A., and Jenkins, R. K. (2007). Seasonal food habits of five sympatric forest microchiropterans in western Madagascar. J. Mammal. 88, 959-966.

Rakotomanana, H., Hino, T., Kanzaki, M., and Morioka, H. (2003). The role of the Velvet Asity Philepitta castanea in regeneration of understory shrubs in Madagascan rainforest. Ornithol. Sci. 2, 49-58. doi: 10.2326/osj.2.49

Ramananjato, V., Rakotomalala, Z., Park, D. S., DeSisto, C. M. M., Raoelinjanakolona, N. N., Guthrie, N. K., et al. (2020). The role of nocturnal omnivorous lemurs as seed dispersers in Malagasy rain forests. Biotropica 52, 758-765. doi: 10.1111/btp.12789

Ramananjato, V., and Razafindratsima, O. H. (2021). Structure of microhabitat used by Microcebus rufus in a heterogenous landscape. Int. J. Primatol. doi: 10.1007/s10764-021-00224-4

Razafindratsima, O. H. (2014). Seed dispersal by vertebrates in Madagascar's forests: review and future directions. Madag. Conserv. Dev. 9, 90-97.

Razafindratsima, O. H. (2017). Post-dispersal seed removal by rodents in Ranomafana rain forest. Madag. J. Trop. Ecol. 33, 232-236. doi: 10.1017/ S0266467417000104

Razafindratsima, O. H., Brown, K. A., Carvalho, F., Johnson, S. E., Wright, P. C., and Dunham, A. E. (2017). Data from: Edge effects on Components of Diversity and Above-Ground Biomass in a Tropical Rainforest. Dryad Data Repository, doi: 10.5061/dryad.jn743

Razafindratsima, O. H., Brown, K. A., Carvalho, F., Johnson, S. E., Wright, P. C., and Dunham, A. E. (2018a). Edge effects on components of diversity and above-ground biomass in a tropical rainforest. J. Appl. Ecol. 55, 977-985. doi: $10.1111 / 1365-2664.12985$

Razafindratsima, O. H., and Dunham, A. E. (2015). Assessing the impacts of nonrandom seed dispersal by multiple frugivore partners on plant recruitment. Ecology 96, 24-30. doi: 10.1890/14-0684.1

Razafindratsima, O. H., and Dunham, A. E. (2016). Frugivores bias seed-adult tree associations through non-random seed dispersal: a phylogenetic approach. Ecology 97, 2094-2102.

Razafindratsima, O. H., and Dunham, A. E. (2019). Fruit/Seed traits and Phenology of Trees in Ranomafana National Park, Madagascar. Dryad Data Repository, doi: 10.5061/dryad.g4n11

Razafindratsima, O. H., Gentles, A., Drager, A. P., Razafimahaimodison, J.-C., Razalazampirenena, C. J., and Dunham, A. E. (2018b). Consequences of lemur loss for above-ground carbon stocks in a Malagasy rainforest. Int. J. Primatol. $39,415-426$.

Razafindratsima, O. H., Tonos, J. L., Ramananjato, V., Dunham, A. E., and Andriamavosoloarisoa, M. (in press) "Frugivory and seed dispersal," in The New Natural History of Madagascar, eds S. M. Goodman and J. P. Benstead (Princeton, NJ: Princeton University Press).

Razafindratsima, O. H., Yacoby, Y., and Park, D. S. (2018c). Data from: MADA: Malagasy Animal Trait Data Archive. Dryad Data Repository, doi: 10.5061/ dryad.44tt0

Razafindratsima, O. H., Yacoby, Y., and Park, D. S. (2018d). MADA: malagasy animal trait data archive. Ecology 99, 990-990. doi: 10.1002/ecy.2167

Rehm, E. M., Chojnacki, J., Rogers, H. S., and Savidge, J. A. (2018). Differences among avian frugivores in seed dispersal to degraded habitats. Restor. Ecol. 26, 760-766. doi: $10.1111 /$ rec. 12623

Rendigs, A., Radespiel, U., Wrogemann, D., and Zimmermann, E. (2003). Relationship between microhabitat structure and distribution of mouse lemurs (Microcebus spp.) in northwestern Madagascar. Int. J. Primatol. 24, 47-64. doi: 10.1023/A:1021494428294

Restrepo, C., Gomez, N., and Heredia, S. (1999). Anthropogenic Edges, treefall gaps, and fruit-frugivore interactions in a neotropical montane forest. Ecology 80, 668-685. doi: 10.1890/0012-9658(1999)080[0668:AETGAF]2.0.CO;2

Ries, L., Fletcher, R. J., Battin, J., and Sisk, T. D. (2004). Ecological responses to habitat edges: mechanisms, models, and variability explained. Ann. Rev. Ecol. Evol. Syst. 35, 491-522. doi: 10.1146/annurev.ecolsys.35.112202.130148

Rogers, H. S., Buhle, E. R., HilleRisLambers, J., Fricke, E. C., Miller, R. H., and Tewksbury, J. J. (2017). Effects of an invasive predator cascade to plants via mutualism disruption. Nat. Commun. 8:14557. doi: $10.1038 /$ ncomms 14557

Ruffell, J., and Didham, R. K. (2016). Towards a better mechanistic understanding of edge effects. Landsc. Ecol. 31, 2205-2213. doi: 10.1007/s10980-016-0397-3

Santos, B. A., Arroyo-Rodríguez, V., Moreno, C. E., and Tabarelli, M. (2010). Edge-related loss of tree phylogenetic diversity in the severely fragmented Brazilian Atlantic forest. PLoS One 5:e12625. doi: 10.1371/journal.pone.0012625

Santos, B. A., Peres, C. A., Oliveira, M. A., Grillo, A., Alves-Costa, C. P., and Tabarelli, M. (2008). Drastic erosion in functional attributes of tree assemblages in Atlantic forest fragments of northeastern Brazil. Biol. Conserv. 141, 249-260. doi: 10.1016/j.biocon.2007.09.018

Seaman, D., Randriahaingo, H. N., Randrianarimanana, H. L., Ravaloharimanitra, M., Humle, T., and King, T. (2018). Edge effects on indri and black-and-white ruffed lemur distribution in the Andriantantely lowland rainforest, eastern Madagascar. Lemur News 21, 51-56.

Semprebon, G. M., Godfrey, L. R., Solounias, N., Sutherland, M. R., and Jungers, W. L. (2004). Can low-magnification stereomicroscopy reveal diet? J. Hum. Evol. 47, 115-144. doi: 10.1016/j.jhevol.2004.06.004

Tylianakis, J. M., Didham, R. K., Bascompte, J., and Wardle, D. A. (2008). Global change and species interactions in terrestrial ecosystems. Ecol. Lett. 11, 13511363. doi: 10.1111/j.1461-0248.2008.01250.x

Uhl, C. (1987). Factors controlling succession following slash-and-burn agriculture in Amazonia. J. Ecol. 75, 377-407. doi: 10.2307/2260425

Vieilledent, G., Grinand, C., Rakotomalala, F. A., Ranaivosoa, R., Rakotoarijaona, J.-R., Allnutt, T. F., et al. (2018). Combining global tree cover loss data with historical national forest cover maps to look at six decades of deforestation and forest fragmentation in Madagascar. Biol. Conserv. 222, 189-197. doi: 10.1016/ j.biocon.2018.04.008 
Vinutha, H. P., Poornima, B., and Sagar, B. M. (2018). "Detection of outliers using interquartile range technique from intrusion dataset," in Information and Decision Sciences Advances in Intelligent Systems and Computing, eds S. C. Satapathy, J. M. R. S. Tavares, V. Bhateja, and J. R. Mohanty (Singapore: Springer), 511-518. doi: 10.1007/978-981-10-75 63-6_53

Wandrag, E. M., Dunham, A. E., Miller, R. H., and Rogers, H. S. (2015). Vertebrate seed dispersers maintain the composition of tropical forest seedbanks. $A o B$ Plants 7:lv130. doi: 10.1093/aobpla/plv130

Wenny, D. G. (2000). Seed dispersal, seed predation, and seedling recruitment of a neotropical montane tree. Ecol. Monogr. 70, 331-351. doi: 10.1890/00129615(2000)070[0331:SDSPAS]2.0.CO;2

Wunderle, J. M. Jr. (1997). The role of animal seed dispersal in accelerating native forest regeneration on degraded tropical lands. For. Ecol. Manag. 99, 223-235. doi: 10.1016/S0378-1127(97)00208-9

Young, K. R., Ewel, J. J., and Brown, B. J. (1987). Seed dynamics during forest succession in Costa Rica. Vegetatio 71, 157-173.
Conflict of Interest: The authors declare that the research was conducted in the absence of any commercial or financial relationships that could be construed as a potential conflict of interest.

Publisher's Note: All claims expressed in this article are solely those of the authors and do not necessarily represent those of their affiliated organizations, or those of the publisher, the editors and the reviewers. Any product that may be evaluated in this article, or claim that may be made by its manufacturer, is not guaranteed or endorsed by the publisher.

Copyright (c) 2021 Razafindratsima, Raoelinjanakolona, Heriniaina, Nantenaina, Ratolojanahary and Dunham. This is an open-access article distributed under the terms of the Creative Commons Attribution License (CC BY). The use, distribution or reproduction in other forums is permitted, provided the original author(s) and the copyright owner(s) are credited and that the original publication in this journal is cited, in accordance with accepted academic practice. No use, distribution or reproduction is permitted which does not comply with these terms. 